\title{
Theoretical Investigation of Aspect Ratio of Heliostat to Minimize Capital Cost of Solar Tower Plant
}

\author{
Rakesh Singhai, Harender, N.D. Banker* \\ Department of Mechanical Engineering, \\ Shiv Nadar University, Uttar Pradesh -201314, India.
}

\begin{abstract}
Electricity generation with solar energy using solar tower integrated with thermal energy storage is a promising technology over solar PV system which needs expensive and non-ecofriendly battery for electricity storage. However, the capital cost of the solar tower plant is quite high. In an effort to bring down the cost, this paper presents theoretical investigation of aspect ratio of heliostats which carry substantial cost of the total solar tower plant. It is known fact that heliostat design is influenced significantly by the wind loads. Several researchers have shown that optimum area of a heliostat is determined by the design wind speed considering a square heliostat. This paper looks at the aspect ratio as an important variable to be considered for optimizing the cost $/ \mathrm{m}^{2}$ of a heliostat. It is established that appropriate aspect ratio coupled with the optimum area has a significant impact on the cost $/ \mathrm{m}^{2}$ of a heliostat and the influence of aspect ratio increases with increase in design wind speed. It is observed that at design wind speed of $6 \mathrm{~m} / \mathrm{s}$, the cost $/ \mathrm{m}^{2}$ gets reduced by $2.8 \%$, while it is $5.08 \%$ for $12 \mathrm{~m} / \mathrm{s}$. It is estimated that for a $20 \mathrm{MW}$ PT plant with $150000 \mathrm{~m}^{2}$ heliostat field and a design wind speed of 12 $\mathrm{m} / \mathrm{s}$, the reduction in capital cost will be about US\$ 0.8 million.
\end{abstract}

Keywords: Heliostat design; Wind loads; Aspect ratio; Solar tower plant; Wind speed; Capital cost.

\section{INTRODUCTION}

In recent years, solar energy has become one of the prominent sources of energy to fulfill the world's energy demand due to its natural availability without any negative impact on the environment [1]. The solar power can be harnessed by solar photovoltaic (PV) as well as solar thermal technologies. Most of the solar energy generation all over the world is based on solar photovoltaic (PV). However due to its intermittent nature, solar from PV cannot address the fluctuating electricity demand, which peaks in the evening hours when solar energy is unavailable. This issue can be resolved if the solar energy could be stored and supplied as per the demand. In solar PV, although the storage can be created using batteries, this is a very expensive proposition and the batteries need to be replaced at regular intervals. Moreover, the disposal of the battery waste is not environment friendly [2]. In this context, the concentrated solar thermal power with storage becomes a potential alternative. Concentrated solar thermal power plants utilize a eutectic mixture of salts for storage of solar energy in the form of heat. This salt mixture is environmentally benign unlike batteries [3]. Concentrated solar thermal power plants are of two kinds, namely Parabolic trough and Power tower (PT). Both of these can be configured to store solar energy in the form of heat and convert it to electrical energy using steam turbines.

Parabolic trough plants without storage have been widely used and capacity to produce several thousand $\mathrm{MW}$ is in place worldwide [4]. Solar tower is a relatively new technology but it is now booming with several new projects at a commercial scale in the operational and construction phase [5]. PT plants score immensely over the parabolic trough plants in their ability to allow storage of thermal energy [6]. Parabolic trough plants too can store energy but because of their design involving 50150 kilometers of horizontal pipelines for a typical $50 \mathrm{MW}$ plant, chances of molten salt freeze out in the receiver lines and headers is a major concern [7]. PT plants do not have this issue.

By storing thermal energy using molten salts, PT plants can be designed to operate 24 hours a day and thus be operated like a base load plant similar to a coal fired thermal power plant. Latest $110 \mathrm{MW}$ solar tower plant at Crescent Dunes in USA, built by Solar Reserve is an excellent testimony to the success of solar tower power technology. It is now fully integrated into the grid and running successfully. It produces power to meet demand with storage capacity of 10 hours of full output [8]. However to make the PT plants a mainstay of electricity production, it is very important to reduce the cost of energy from such plant close to the power cost of a fossil fuel plant. At present power from coal costs about US\$ $0.06 / \mathrm{kWh}$, whereas latest PT plant at Crescent Dunes has a power purchase agreement at US\$0.13/kWh [9].

In an effort to reduce costs for PT, this paper focuses on reduction of capital cost for the solar tower power plant. It suggests a way to reduce capital costs by bringing down heliostat field cost, which is a very large component of PT plant cost [10]. The heliostat field consists of thousands of heliostats

${ }^{*}$ Corresponding author: Rakesh Singhai
E-mail: rs362@snu.edu.in 
around a high tower. They all direct the solar radiation falling on them to the tower. A heliostat is essentially a mirror which is tracked in two axes continuously to ensure that the solar radiation falling on it is directed towards the receiver located at the top of the tower. The cost of the heliostat field could be up to $40-50 \%$ of the total project cost of a tower project [11].

During the literature survey, it became increasingly clear that the design of the heliostat is highly dependent on the wind loads [12]. In fact, wind loads are the decisive factors for dimensioning of heliostats [13]. A heliostat is designed to track the sun and accurately reflect the radiation onto the receiver on a high tower. Due to the long distance between the tower and a heliostat, the accuracy of reflection has to be very high and hence, the loads on heliostat play a very important role.

Among the early heliostats, $148 \mathrm{~m}^{2}$ ATS heliostat developed in late 80 s was considered a good safe design as it had been used for several years and withstood extreme weather and wind loads too [14]. Also at that time, it was felt that bigger the heliostat, lower would be the cost of heliostat field as lesser numbers of heliostats would be required for the same area [15]. But this view was changed later by Blackmon [11] who carried out a detailed cost analysis of the ATS heliostat and developed algorithm to parametrically determine the heliostat cost as a function of its mirror area and determined that smaller heliostats in the range of $40-50 \mathrm{~m}^{2}$ would be much more economical for a wind speed of $12 \mathrm{~m} / \mathrm{s}$.

Heliostat design is based upon a mean design wind speed (DWS). DWS is the mean wind speed up to which the heliostat is designed to operate with accurate tracking and over which the reflector panel of the heliostat becomes flat in order to reduce the wind loads on it very significantly and thus save itself from any damage [12] . This speed is largely chosen based upon local wind speed data and the local civil engineering codes. If a DWS lower than the maximum prevailing wind speed is chosen, it may sacrifice the energy output but it most definitely reduces the cost of heliostat field. Depending upon the location and wind speed prevalent there, it is possible to reduce the cost of energy by choosing a DWS which is lower than standard [16]. Since wind loads have an important bearing on heliostat costs and heliostats with different aspect ratio (width/height) lead to change in wind loads, it should be investigated if costs can be further reduced by optimizing the aspect ratio of a heliostat [13].

This paper combines the approach given by Emes et al. [16] of obtaining lowest capital cost for heliostat by determining an optimum area of square heliostat as a function of DWS and the procedure followed by Pfahl et al. [13] to obtain optimum aspect ratio for the selected heliostat area, which in turn will provide optimum heliostat cost.

\section{METHODOLOGY}

A procedure to estimate total PT plant capital cost has been explained in flow chart shown in Figure 1.

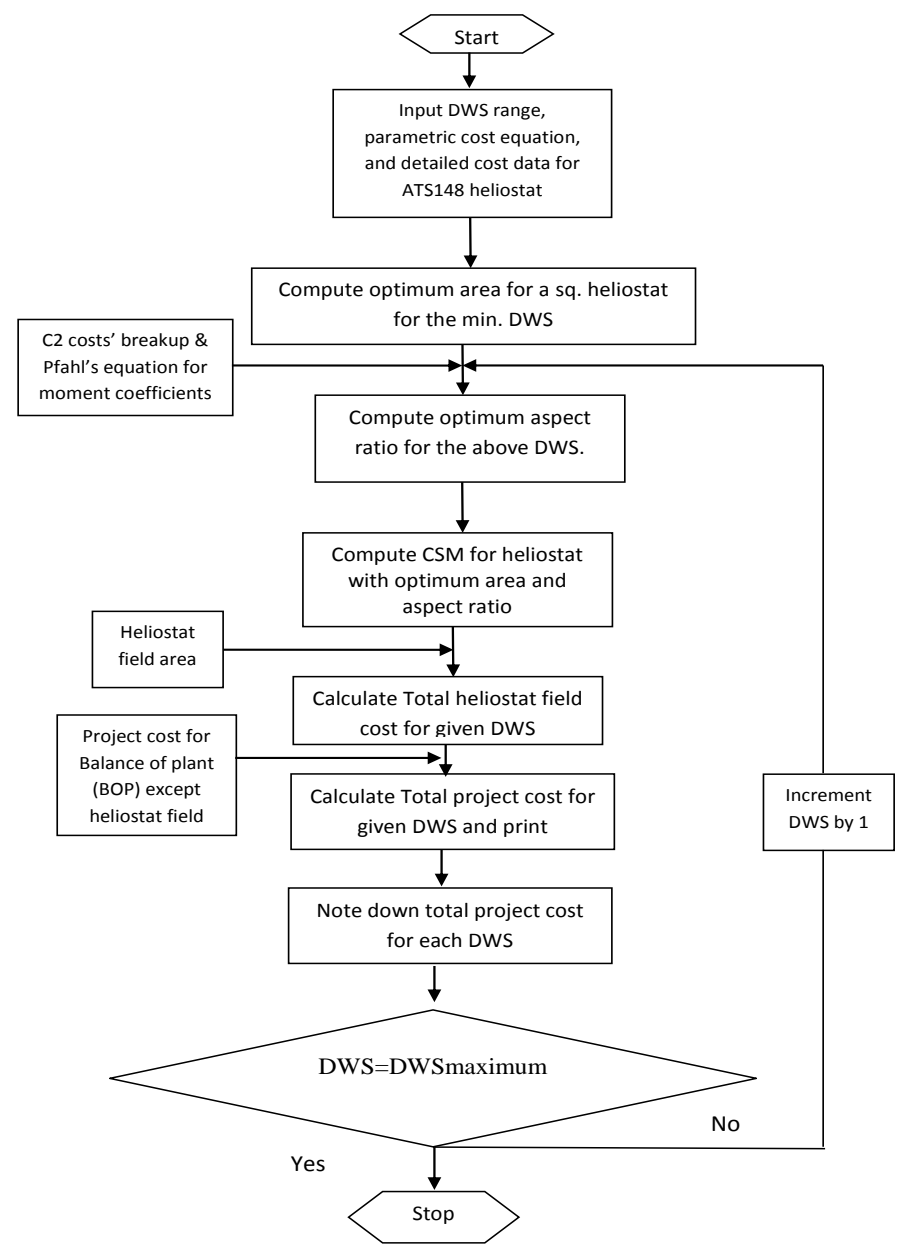

Figure 1: Flow chart for PT plant capital cost with respect to DWS

As described in the flow chart, for the calculation of total project cost, the optimum area of a square heliostat is determined, using the parametric cost equation mentioned by Blackmon [17] suitably amended to incorporate DWS as a variable. Pfahl et al. [13] reported that for different aspect ratios, the wind load coefficients for various moment loads over the heliostat will be different and wind load moments are important factors in the sizing of various heliostat components. By using these modified wind load coefficients, optimum aspect ratio has been obtained for the selected optimum square heliostat and heliostat field installed cost per square meter (CSM) has been calculated. Total heliostat field cost is calculated by multiplying the CSM with heliostat field mirror area. All other project costs referred to as "Balance of plant costs" in the flow chart including costs of receiver, tower and power block etc. except for the field cost are taken from PS20 plant [16]. The field area is taken as $150000 \mathrm{~m}^{2}$ [18]. By adding all the costs, the total project cost is computed. PS20 plant has been used as reference for this paper. 


\section{Optimum CSM of a Square Heliostat}

Blackmon [17] has shown that the optimum azimuth-elevation heliostat cost can be determined by analyzing cost relationships in terms of heliostat area parametrically, distributed among three distinct categories. The cost analysis was carried out for the ATS $148 \mathrm{~m}^{2}$ heliostat. Blackmon has broken up the heliostat CSM into three categories. The three categories are described as below.

Category (C1): These costs are constant costs per unit area and are independent of heliostat size for a given heliostat field mirror area (e.g. mirrors).

Category (C2): These costs are size-dependent and are determined by the loads imposed which increase the cost $/ \mathrm{m}^{2}$ as the area increases. (E.g. structure, pylon, foundation, elevation and azimuth drives). Size dependent costs are proportional to three halves power law of area.

Category 3 (C3): These costs are fixed costs for components used on each individual heliostat, irrespective of its size for a given field size. This fixed cost $/ \mathrm{m}^{2}$ increases linearly with the number of heliostats, and thus the cost per unit area increases as the size decreases, and vice versa. (E.g. Controllers, position sensors, limit switches etc.).

CSM was calculated by using the following equation [17],

$$
\mathrm{CSM}=\mathrm{C}_{1}+\mathrm{C}_{2}+\mathrm{C}_{3}=\mathrm{C}_{1}+\mathrm{KA}_{\mathrm{H}}^{0.65}+\frac{\mathrm{f}}{\mathrm{A}_{\mathrm{H}}}
$$

Where $A_{\mathrm{H}}$ the mirror area of heliostat, $K$ is a constant dependent on DWS and $f$ is the fixed installed total cost per heliostat. Based upon the cost breakup of ATS heliostat of $148 \mathrm{~m}^{2}$ cost [17], $\mathrm{C} 1$ is determined as $\$ 34.44 / \mathrm{m}^{2}$.

It can be seen from the equation (1) that the $\mathrm{C} 2$ cost is dependent on wind speed and value of " $K$ " would be proportional to the square of wind velocity.

$$
K=\frac{\left(86.26 / 148^{0.65}\right) D W S^{2}}{12^{2}}
$$

Where, $\$ 86.26$ is the $\mathrm{C} 2$ cost $/ \mathrm{m}^{2}$ of ATS $148 \mathrm{~m}^{2}$ heliostat for DWS of $12 \mathrm{~m} / \mathrm{s}$ and $f$ is the fixed cost per heliostat, irrespective of its size. (Values taken from the ATS $148 \mathrm{~m}^{2}$ heliostat cost break up).

$$
f=\$ 1332(148 \times 9)
$$

By differentiating equation (1) with respect to $A_{\mathrm{H}}$ and setting the derivative to zero, the optimum area of a square heliostat is obtained as

$$
\mathrm{A}_{\text {H/OPTIMUM }}=(\mathrm{f} / 0.65 \mathrm{~K})^{1 / 1.65}
$$

Using the above derived optimum area, the optimum CSM for a square heliostat was computed. By choosing optimum area Blackmon showed the reduction in CSM from $\$ 129 / \mathrm{m}^{2}$ to $\$ 90 / \mathrm{m}^{2}$ for a square heliostat at DWS of $12 \mathrm{~m} / \mathrm{s}$. In the present work, optimum CSM has been calculated for each DWS from $3 \mathrm{~m} / \mathrm{s}$ to $25 \mathrm{~m} / \mathrm{s}$ in steps of 1 .

\section{Optimum Aspect Ratio}

Many investigators have found the optimum area of a square heliostat as a function of DWS but the impact of different aspect ratios (width/height) on the cost of heliostat and hence total cost of the PT plant has not been explored fully. Pfahl had undertaken study of wind loads on heliostats with different aspect ratios [13]. He had carried out wind tunnel studies to establish the wind load coefficients for various components of forces and moments on heliostats. The wind load coefficients for square heliostat were established by Peterka [19] by extensive wind tunnel testing on square shaped heliostat mirrors. Pfahl et al. did the wind tunnel testing on heliostat mirrors of varying aspect ratios and determined the unified equations to predict wind load coefficients as a function of the aspect ratio. The coordinate system used for this analysis is depicted in Figure 2. Abbreviations used below are depicted in Figure 2 for purpose of clarity. Figure 3 gives the flow chart used for the computation of optimum aspect ratio.

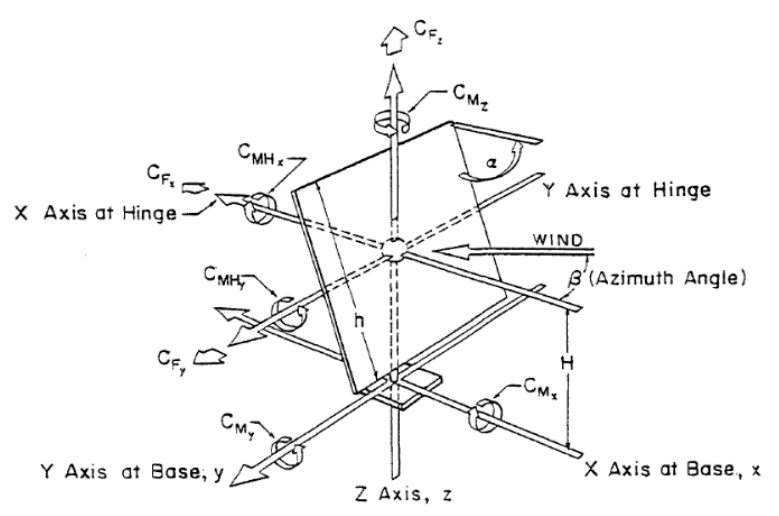

Figure 2: Coordinate system [20]

The wind load coefficients of peak loading were considered for the purpose of heliostat design. It was observed that they were much larger than mean values in all cases. The coefficients were determined by extensive wind tunnel testing using $18 \%$ turbulence intensity (TU), which is the norm for a typical open country environment of a PT plant [13].

Peak load on elevation drive, $M H_{Y}$ (Peak) will occur when $C_{M H_{Y}}$ is highest which is obtained for elevation angle $(\alpha)$ of $30^{0}$ and azimuth angle $(\beta)$ of $0^{0}$.The value chosen for $C_{M H_{Y}}$ is 0.6. It is seen that $C_{M H_{Y}}$ is 0.25 for mean loads and thus the peak load is 2.4 times larger than mean load. Peak load on azimuth drive, $M_{Z}$ occurs for elevation angle $(\alpha)$ of $90^{\circ}$ and azimuth angle $(\beta)$ of $65^{\circ}$ and the value of $C_{M_{Z}}$ is given as 0.7 which is used to compute maximum load on azimuth drive for design consideration [20].

The following equations given by Pfahl for moments were used to calculate the three moments for heliostats with varying aspect ratios [13]. Aspect ratio $r_{a}$ is defined as ratio of width to height $(\mathrm{b} / \mathrm{h})$ of the heliostat area.

$$
\mathrm{P}_{\text {Dyn. }}=1 / 2 \rho \mathrm{V}^{2}
$$




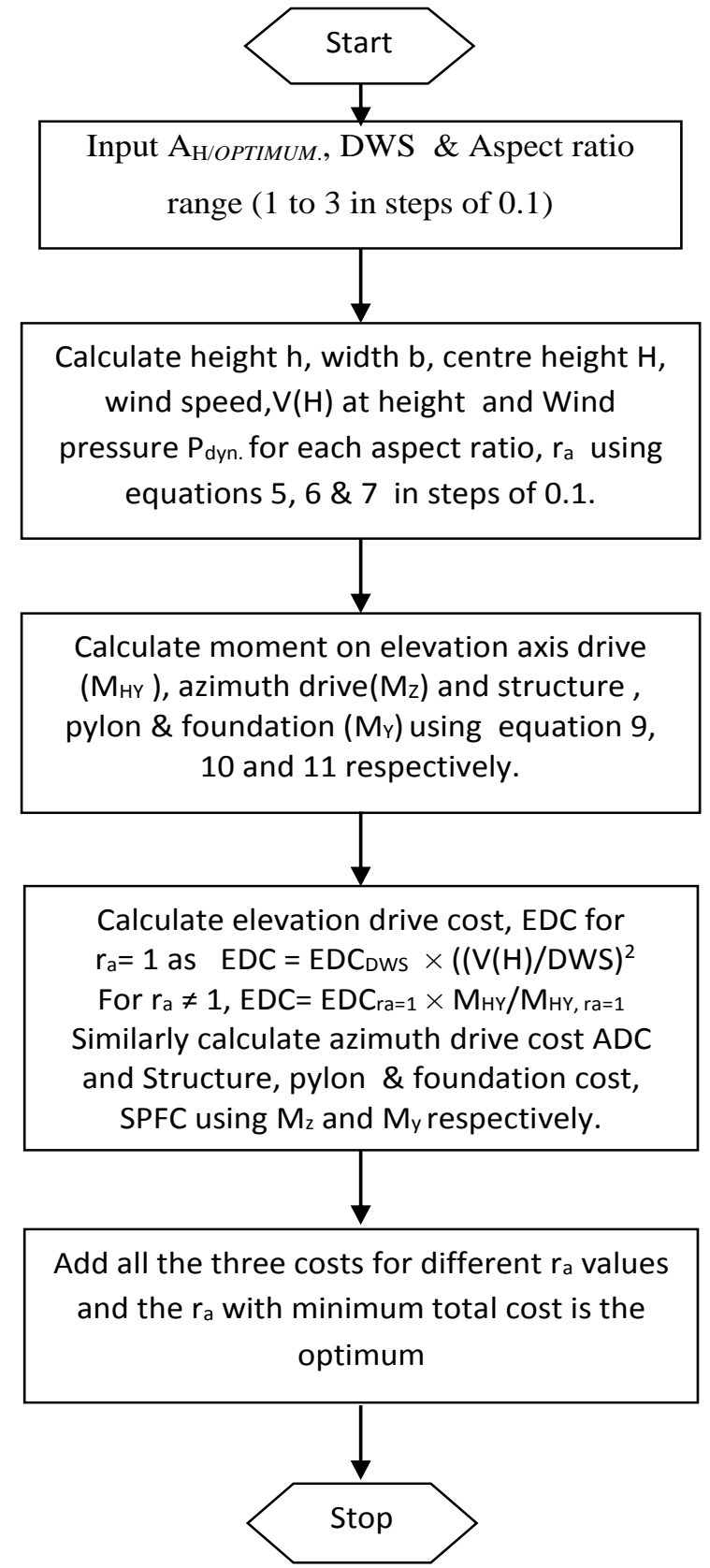

Figure 3: Flow chart for the optimization of aspect ratio of a heliostat

This is the standard expression for wind pressure. $\mathrm{V}(\mathrm{H})$, the mean wind velocity was calculated using power law equation as below. Mean Hourly Wind Speed data was taken as $\mathrm{V}_{\text {ref }}$. Reference height for $\mathrm{V}_{\text {ref }}$ was taken as 10 meters.

$$
\frac{V(H)}{V_{\text {ref. }}}=\left(\frac{Z}{Z_{0}}\right)^{0.15}
$$

Center height,

$$
H=1.25+h / 2
$$

Above formula for center height $(\mathrm{H})$ was chosen to ensure that heliostat base has a minimum clearance of $1.25 \mathrm{~m}$ from ground so that the glass is not damaged by rocks/pebbles from ground [17].

Peak load on structure, pylon and foundation $\left(M_{Y}\right)$ was computed using the following eqn.

$$
M_{Y}=F_{X} \times \mathrm{H}+M H_{Y}
$$

Peak $M_{Y}$ occurs for elevation angle $(\alpha)$ of $90^{\circ}$ and azimuth angle $(\beta)$ of $0^{0}$. At this position, $C_{F_{X}}$ is 4.0 and the corresponding peak coefficient is 0.25 not 0.6 which was used for computation of $\mathrm{MH}_{Y}$.

$$
\begin{aligned}
& M_{Z}=C_{M_{Z}} P_{D y n .} A_{H} b \\
& M H_{Y}=1.2 C_{M H_{Y}} P_{D y n .} A_{H} h r_{a}^{0.2} \\
& F_{X}=C_{F_{X}} P_{D y n .} A_{H}
\end{aligned}
$$

The three moments $M H_{Y}, M_{\mathrm{Y}}$ and $M_{Z}$ for varying aspect ratios from 1 to 3 in steps of 0.1 were calculated using the coefficients developed by Pfahl. These moments were multiplied by the respective cost coefficients using Blackmon's parametric model to obtain the total cost of these three "C2" types of cost. Important point to note here is the weightage that was given to elevation and azimuth drive costs. The NREL report prepared by Sargent and Lundy stated that the elevation drives are relatively much cheaper than azimuth drives. This is because elevation drives are constructed using linear actuators while azimuth drives use complex gearboxes. This differentiation was effectively used in our overall cost computation of the three "C2" costs. Elevation drive was given $24 \%$ weight compared to $76 \%$ for azimuth drive, out of total drive costs [4].

This exercise was repeated for different DWS from 3 to $25 \mathrm{~m} / \mathrm{s}$. in steps of 1 . It was observed in our studies that the optimum aspect ratio changes with DWS. The impact of the reduction of these three costs as a percentage of the cost $/ \mathrm{m}^{2}$ of an equivalent square heliostat was obtained. Thus, not just the optimum area but also optimum aspect ratio required for a heliostat as a function of DWS was obtained. While computing these moments, the change in height of the heliostat due to change in aspect ratio was accounted for, which led to change in wind load based upon the power law.

\section{RESULTS AND DISCUSSION}

\section{Optimum Area and CSM of a Heliostat}

For the entire range of DWS from 3 to $25 \mathrm{~m} / \mathrm{s}$, the optimum area and CSM have been plotted as shown in Figure 4. It is observed from the Figure that CSM increases with increase in DWS, due to the reason that the wind loads are proportional to square of wind speed, leading to higher loads and consequently increasing the costs for a given size of heliostat. On the other hand optimum area is inversely proportional to $\mathrm{K}$ (refer equation 4). This leads to lower optimum area with respect to higher DWS.

It can be depicted from the Figure 4 that the optimum area is 20 $\mathrm{m}^{2}$ for a DWS of $25 \mathrm{~m} / \mathrm{s}$, while it increases to a high of $262 \mathrm{~m}^{2}$ 
for $3 \mathrm{~m} / \mathrm{s}$ speed. This shows a wide range of possible heliostat sizes due to change in DWS. At $12 \mathrm{~m} / \mathrm{s}$ wind speed, the optimum CSM is US\$103.7 compared to \$129.7 for the ATS heliostat, which is a reduction of $20 \%$ by choosing the optimum area as $49 \mathrm{~m}^{2}$ instead of the original $148 \mathrm{~m}^{2}$. At $9 \mathrm{~m} / \mathrm{s}$ DWS the optimum cost would be US $\$ 91.97 / \mathrm{m}^{2}$ which is $29 \%$ cheaper than ATS heliostat cost and at $7 \mathrm{~m} / \mathrm{s}$ DWS the optimum cost at US $\$ 72.8 / \mathrm{m}^{2}$ is $44 \%$ cheaper.This clearly brings out the importance of choosing the correct DWS. It has a large impact on the plant cost as heliostat field cost is a very significant part of the overall costs.

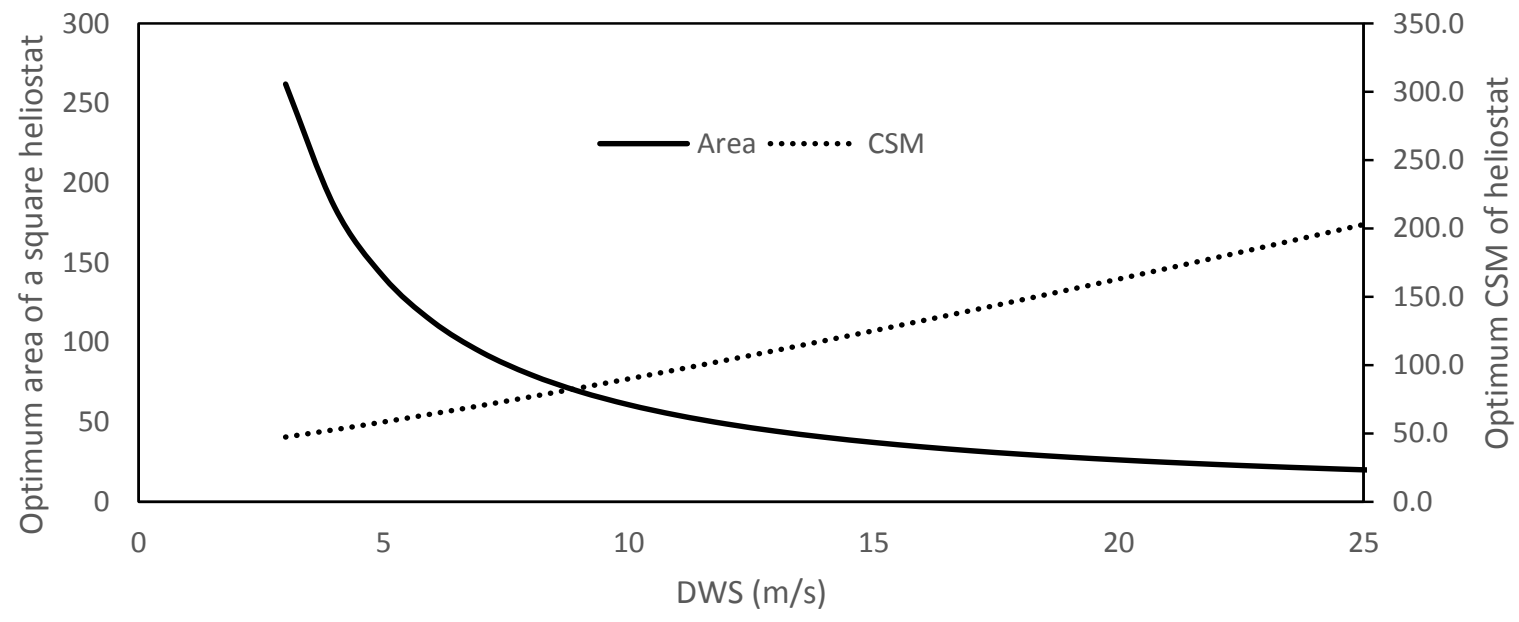

Figure 4: Optimum mirror area and optimum heliostat CSM with variation in DWS

\section{Optimum Aspect Ratio}

Variation in the cost of elevation and azimuth drives and structure with respect to aspect ratio of heliostat for a DWS of $15 \mathrm{~m} / \mathrm{s}$ has been shown in Figure 5. It shows that the elevation drive cost falls as the aspect ratio increases and the structure cost also follows the same trend, whereas the azimuth drive cost increases with increase in aspect ratio. For a given area of heliostat as the aspect ratio increases, the elevation axis height
$\mathrm{H}$ of heliostat gets reduced which in turn leads to reduction in wind pressure and thus reducing $M H_{Y} . M H_{Y}$ is directly proportional to Elevation drive cost, hence elevation drive cost reduces. Similarly the structural cost also falls due to reduction in the wind load. For the azimuth drive, the wind loads are dependent on width $b$, which increases with increase in aspect ratio, leading to higher azimuth drive cost. Since, one cost is increasing and other two are reducing, a distinct optimum aspect ratio for each DWS is obtained.

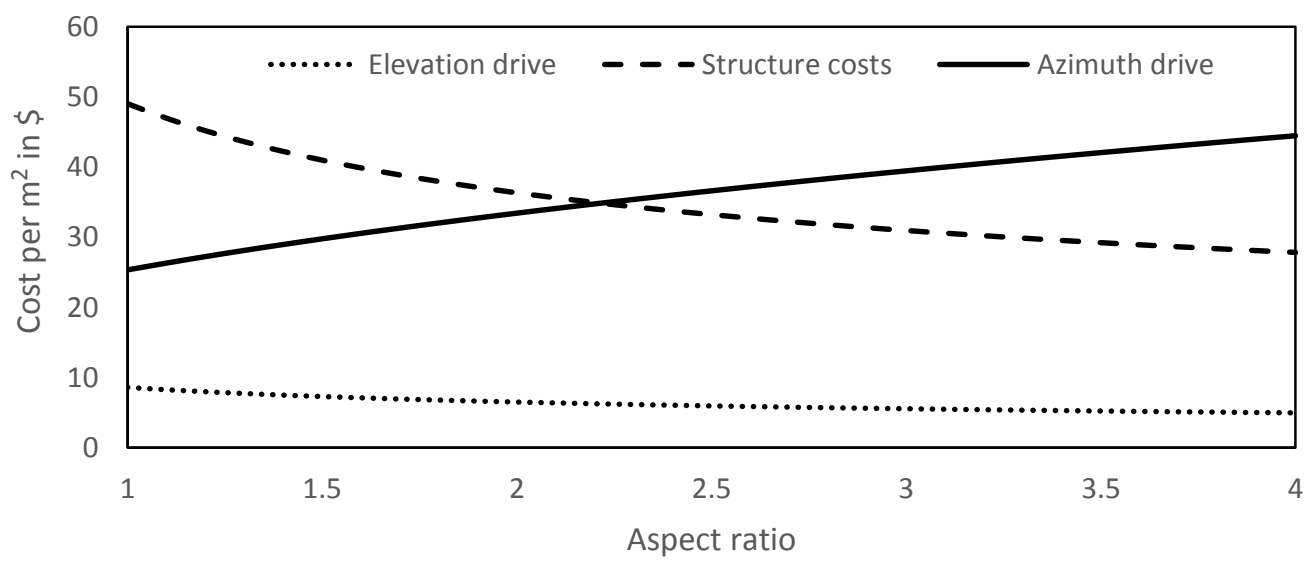

Figure 5: Various C2 elements costs $/ \mathrm{m}^{2}$ change with aspect ratio for DWS of $15 \mathrm{~m} / \mathrm{s}$ 
International Journal of Applied Engineering Research ISSN 0973-4562 Volume 13, Number 18 (2018) pp. 13652-13659

(C) Research India Publications. https://dx.doi.org/10.37622/IJAER/13.18.2018.13652-13659

Figure 6 demonstrates the overall $\mathrm{C} 2$ costs as a function of aspect ratio. Overall C2 costs fall from $\$ 83.04 / \mathrm{m}^{2}$ to $\$ 75.82 / \mathrm{m}^{2}$ for the optimum aspect ratio of 2.6 and the total CSM at DWS of $15 \mathrm{~m} / \mathrm{s}$ fall from $\$ 125.2 / \mathrm{m}^{2}$ to $\$ 117.97$. Thus a $5.75 \%$ reduction is seen in the CSM due to switch to a rectangular reflector panel from a square reflector panel for DWS of $15 \mathrm{~m} / \mathrm{s}$.

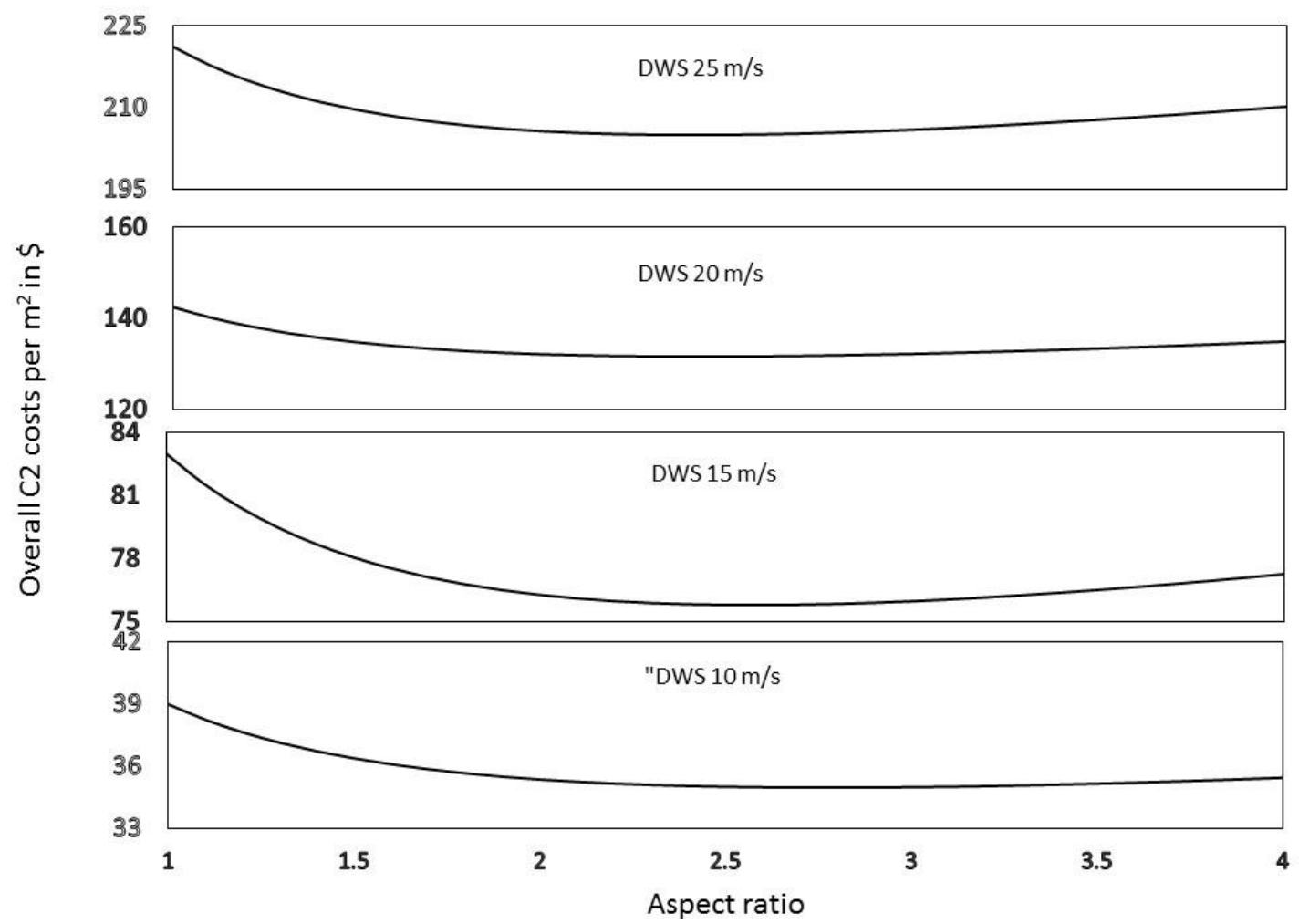

Figure 6: Overall $\mathrm{C} 2$ costs $/ \mathrm{m}^{2}$ with respect to aspect ratio for various DWS

The percentage reduction in overall CSM of a $37 \mathrm{~m}^{2}$ heliostat (optimum size for DWS of $15 \mathrm{~m} / \mathrm{s}$ ) as a result of changing aspect ratio is plotted in Figure 7. Optimum reduction is seen at an aspect ratio of 2.6. The reduction in $\mathrm{C} 2$ cost is more than $15 \%$ for DWS of $15 \mathrm{~m} / \mathrm{s}$.

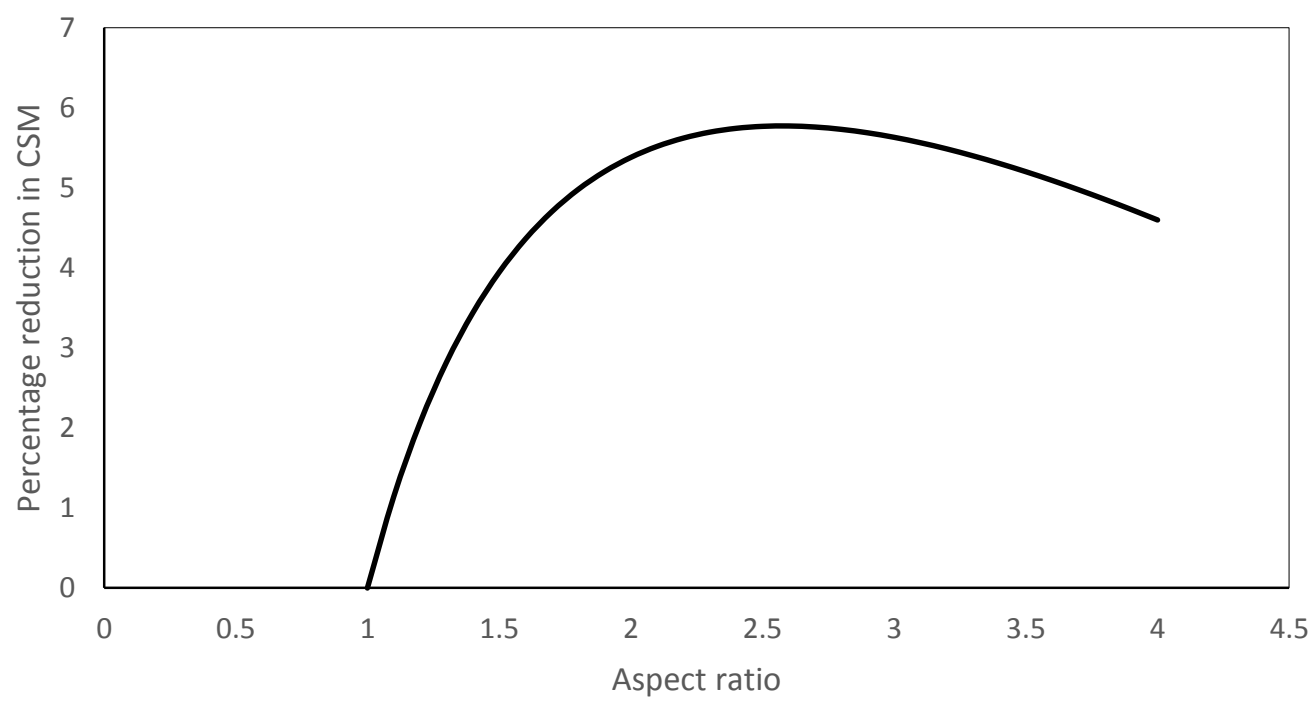

Figure 7: Percentage reduction in CSM with aspect ratio for $37 \mathrm{~m}^{2}$ heliostat 
Figure 8 illustrates the trend of optimum aspect ratio as a function of DWS. It can be seen that optimum aspect ratio reduces as DWS is increased. This happens as the increase in DWS has a much larger impact on Azimuth drive cost than on the elevation and structure costs put together. As the DWS increases, the optimum aspect ratio starts getting lower. The optimum is also dependent upon the cost parameter for each drive. Here, we have taken elevation drive to be about $24 \%$ of the total drive costs [4]. The optimum aspect ratio reduces as the DWS increases.

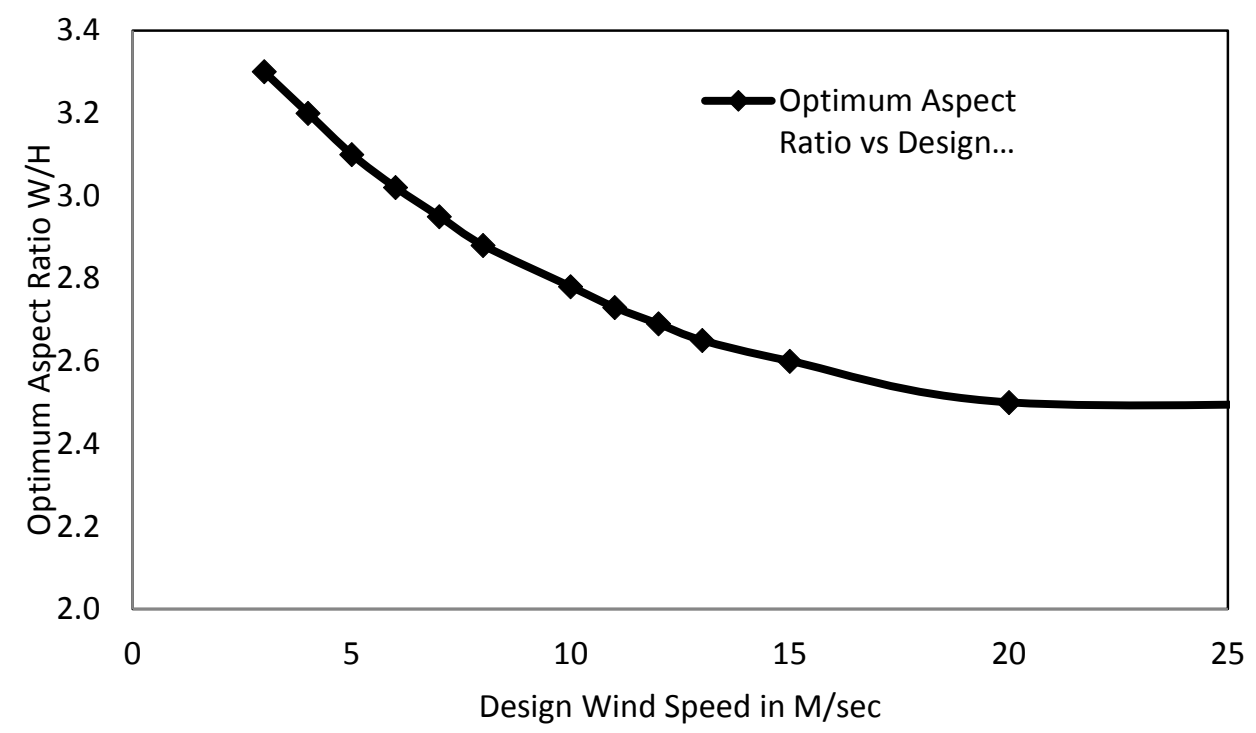

Figure 8: Variation of optimum aspect ratio with DWS

Figure 9 compares the CSM of a square panel heliostat with an optimum rectangular panel heliostat at various DWS. It can be seen clearly that while there is minimal difference in CSM at low wind speeds, it becomes pronounced at higher DWS.

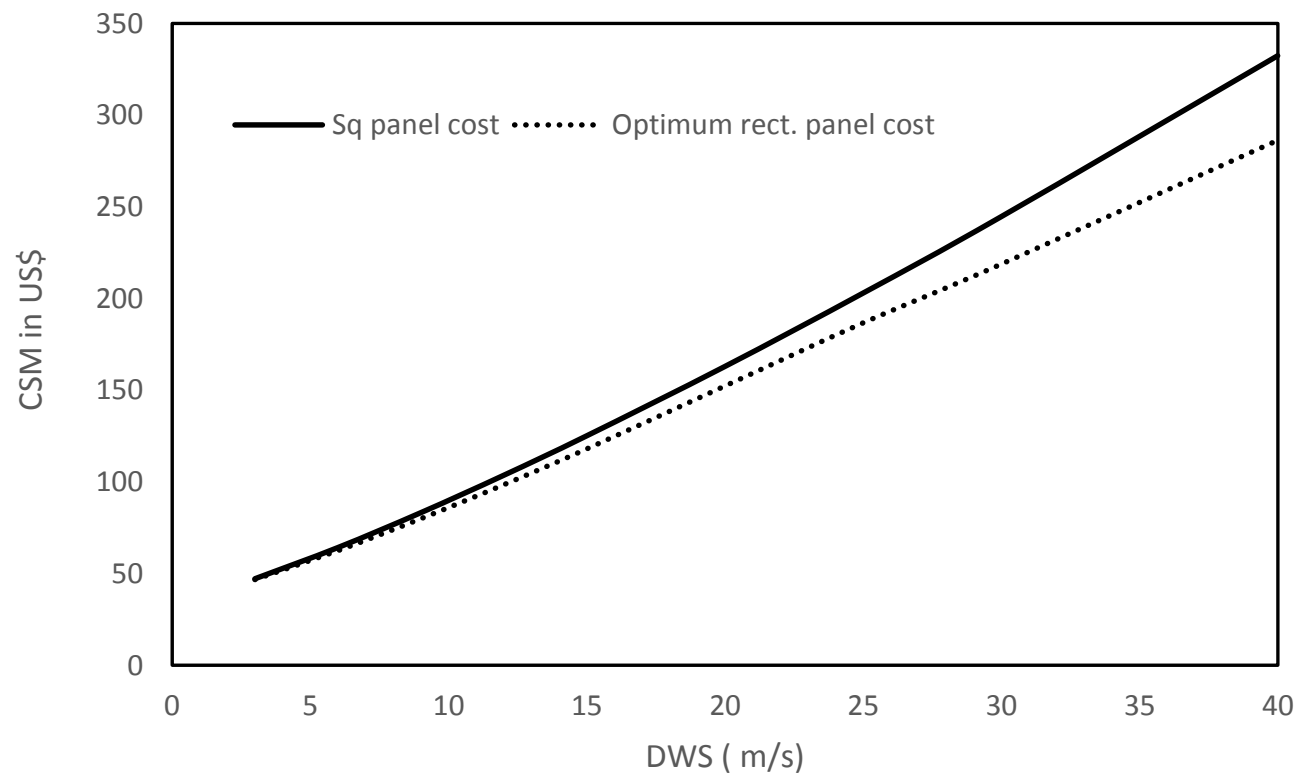

Figure 9: Variation in CSM between square and rectangular panels with DWS 


\section{CONCLUSIONS}

This paper describes the methodology to reduce the capital cost of a solar tower plant by selecting optimum area and aspect ratio of the heliostat, which bears significant cost of the total solar tower plant costs. It is demonstrated in PT plants that not only the heliostat area but the aspect ratio of the heliostats also plays an important role for its cost $/ \mathrm{m}^{2}$. The theoretical analysis shows that at lower design wind speed, the effect of aspect ratio on the heliostat cost is only marginal, while at higher design wind speed it is noticeable. At a design wind speed of $6 \mathrm{~m} / \mathrm{s}$, the cost $/ \mathrm{m}^{2}$ gets reduced by $2.8 \%$, whereas at $12 \mathrm{~m} / \mathrm{s}$, it reduces by $5.08 \%$. It is estimated that by incorporating the optimum aspect ratio of heliostat, the saving in the capital cost of the solar tower plant is about US\$ 0.8 million for a $20 \mathrm{MW} \mathrm{PT}$ plant with $150000 \mathrm{~m}^{2}$ heliostat field at a design wind speed of $12 \mathrm{~m} / \mathrm{s}$.

\section{REFERENCES}

[1] Kristin Seyboth, Sverrisson F, Appavou F, Brown A, Epp B, Leidreiter A, et al. Renewables 2016 Global Status Report. 2016. doi:ISBN 978-3-9818107-0-7.

[2] Battery storage for renewables : market status and technology outlook. 2015.

[3] Way Julie. Storing the Sun : Molten Salt Provides Highly Efficient Thermal Storage. Renew Energy World 2008:1-3.

[4] Sargent \& Lundy LLC Consulting Group Chicago Illinois. Assessment of Parabolic Trough and Power Tower Solar Technology Cost and Performance Forecasts. 2003.

[5] Srilakshmi G, Venkatesh V, Thirumalai NC, Suresh NS. Challenges and opportunities for Solar Tower technology in India. Renew Sustain Energy Rev 2015;45:698-709. doi:10.1016/j.rser.2015.02.016.

[6] Turchi C, Mehos M, Ho CK, Kolb GJ. Current and Future Costs for Parabolic Trough and Power Tower Systems in the US Market Preprint. 2010.

[7] Leitner A. Storage in Power Towers 2017.

[8] Solar Reserve. Crescent Dunes Solar Energy Plant 2016:2015-6.

[9] Concentrating Solar Power Projects - Crescent Dunes Solar Energy Project | Concentrating Solar Power | NREL

n.d. https://www.nrel.gov/csp/solarpaces/project_detail.cf $\mathrm{m} /$ projectID=60 (accessed February 27, 2017).

[10] Towers MP, Kolb GJ. An Evaluation of Possible 2011.

[11] Blackmon JB. Heliostat size optimization for central receiver solar power plants. Conc. Sol. power Technol. SAIC, 2012, p. 536-77. doi:10.1533/9780857096173.3.536.

[12] Murphy LM. Wind loading on tracking and field mounted solar tracker. Golden,Colorado: 1980.

[13] Pfahl A, Buselmeier M, Zaschke M. Wind loads on heliostats and photovoltaic trackers of various aspect ratios. Sol Energy 2011;85:2185-201. doi:10.1016/j.solener.2011.06.006.

[14] Strachan JW, Houser RM. Testing and evaluation of large scale heliostats. 1993.

[15] Kolb GJ, Jones SA, Donnelly MW, Gorman D, Thomas R, Davenport R, et al. Heliostat Cost Reduction Study. 2007.

[16] Emes MJ, Arjomandi M, Nathan GJ. Effect of heliostat design wind speed on the levelised cost of electricity from concentrating solar thermal power tower plants. Sol Energy 2015;115:441-51. doi:10.1016/j.solener.2015.02.047.

[17] Blackmon JB. Parametric determination of heliostat minimum cost per unit area. Sol Energy 2013;97:3429. doi:10.1016/j.solener.2013.08.032.

[18] Concentrating Solar Power Projects - Planta Solar 20 | Concentrating Solar Power | NREL n.d. https://www.nrel.gov/csp/solarpaces/project_detail.cf m/projectID=39 (accessed February 8, 2017).

[19] Peterka JA. Mean and Peak Wind Loads on Heliostats 1989;111.

[20] Peterka J, Derickson R. Wind load design methods for ground based heliostats and parabolic dish collectors. Rep SAND 92-7009 Sandia Natl Lab 1992. 